\title{
Population-based study of amyotrophic lateral sclerosis and occupational lead exposure in Denmark
}

\author{
Aisha S Dickerson, ${ }^{1,2}$ Johnni Hansen, ${ }^{3}$ Aaron J Specht, ${ }^{2}$ Ole Gredal, ${ }^{3}$ \\ Marc G Weisskopf ${ }^{1,2}$
}

- Additional material is published online only. To view please visit the journal online (http://dx.doi.org/10.1136/ oemed-2018-105469).

${ }^{1}$ Department of Epidemiology, Harvard T.H. Chan School of Public Health, Boston, Massachusetts, USA ${ }^{2}$ Department of Environmental Health, Harvard T.H. Chan School of Public Health, Boston, Massachusetts, USA ${ }^{3}$ Occupation Research Unit, Institute of Cancer Epidemiology, Danish Cancer Society Research Center, Copenhagen, Denmark

Correspondence to Dr Aisha S Dickerson, Chan School of Public Health, Environmental and Occupation Medicine and Epidemiology Division of the Department of Environmental Health, Boston MA 02115, USA:

adickerson@hsph.harvard.edu

Received 5 September 2018 Revised 16 November 2018 Accepted 28 November 2018 Published Online First

31 January 2019

\begin{abstract}
Objectives Previous research has indicated links between lead $(\mathrm{Pb})$ exposure and increased risk of neurodegenerative disorders, including amyotrophic lateral sclerosis (ALS). In this study, we evaluated the association between occupational $\mathrm{Pb}$ exposures and ALS. Methods ALS cases were ascertained through the Danish National Patient Registry from 1982 to 2013 and age and sex-matched to 100 controls. Using complete employment history since 1964 from the Danish Pension Fund, cumulative $\mathrm{Pb}$ exposure was estimated for each subject via a Danish job exposure matrix. Associations were evaluated using conditional logistic regression analyses and stratified by sex.
\end{abstract}

Results For men with $>50 \%$ probability of exposure, there was an increase in odds of ALS for exposures in the 60th percentile or higher during any time 5 years prior to diagnosis (aOR: $1.35 ; 95 \% \mathrm{Cl} 1.04$ to 1.76 ) and 10 years prior to diagnosis (aOR: 1.33; $95 \% \mathrm{Cl} 1.03$ to 1.72 ). No significant associations were observed in women, and there were no linear trends seen for $\mathrm{Pb}$ exposures for either sex.

Conclusions Our study indicates an association between consistently higher occupational $\mathrm{Pb}$ exposures and ALS. These findings support those of previously reported associations between ALS and specific occupations that commonly experience $\mathrm{Pb}$ exposure.

\section{INTRODUCTION}

Amyotrophic lateral sclerosis (ALS) is a rapidly progressive neurodegenerative disease with an average survival time of 3-5 years postdiagnosis. ${ }^{1}$ Reports from Denmark indicate an annual incidence of 1-2 new ALS cases per 100000 people. ${ }^{2}$ Although approximately $10 \%$ of ALS cases are attributed to genetic inheritance, ${ }^{3}$ the aetiology of sporadic ALS is not generally understood. However, many hypothesise that ALS may be the result of pre-existing genetic risk and environmental triggers. $^{14}$

Lead $(\mathrm{Pb})$ is one environmental exposure that is a well-known neurotoxicant with previous evidence of cognitive impairment and decline. ${ }^{56} \mathrm{~Pb}$ typically interacts with tissues through transport pathways for calcium and iron and has been shown to enter brain cells primarily through calcium pathways. ${ }^{7}$ Similarly, the neurotoxicity of $\mathrm{Pb}$ is primarily through the disruption of calcium-dependent processes in the brain, altering the release of neurotransmitters, causing oxidative damage and cell death. ${ }^{89}$ Additionally, $\mathrm{Pb}$ can circumvent the blood-brain barrier
Key messages

What is already known about this subject?

- Previous research has indicated links between environmental lead ( $\mathrm{Pb}$ ) exposure and increased risk of neurodegenerative disorders.

- Prior studies of $\mathrm{Pb}$ and amyotrophic lateral sclerosis (ALS) have used retrospectively collected occupation history in small study samples, or occupations at a certain time point.

What are the new findings?

- Men occupationally exposed to Pb at the highest levels in industries with at least $50 \%$ probability of $\mathrm{Pb}$ exposure have a greater risk of ALS.

- Using prospectively collected surveillance data, we observed a consistent positive association across different windows of exposure in men.

How might this impact on policy or clinical practice in the foreseeable future?

- Although $\mathrm{Pb}$ exposures in the general population have been significantly mitigated over the past few decades, more guidelines should be put in place to further protect populations that still experience high $\mathrm{Pb}$ exposures, in particular certain occupations such as construction work.

- Further regulatory action may need to be taken to reduce $\mathrm{Pb}$ exposures from industrial facilities, home renovation activities and roadwork.

and allow further oxidative damage to neural tissue. $^{89}$ Through these disruption pathways and increased susceptibility to environmental insults, $\mathrm{Pb}$ could play a part in substantially increasing the risk of neurological disorders such as ALS, with epidemiological evidence in other neurodegenerative diseases and cognitive function supporting this association. ${ }^{5} 1011$ Some meta-analyses have suggested that exposure to $\mathrm{Pb}$ and other heavy metals may be a risk factor for ALS. ${ }^{12}$ Additionally, increased risk of ALS has been observed in certain occupations with high exposure to $\mathrm{Pb}$, including construction workers, ${ }^{13}{ }^{14}$ military servicemen ${ }^{15} 16$ and mechanics. ${ }^{17} 18$

Although a few studies tried to assess $\mathrm{Pb}$ exposure level in relation to ALS, each used categorical classifications of exposure in relatively small samples. ${ }^{19} 20$ No previous study has used a job exposure matrix 
(JEM) to estimate cumulative $\mathrm{Pb}$ exposure from all jobs held. In this population-based study, we utilise a JEM for an investigation of the relationship between Pb exposure and ALS in Denmark using data from nationwide Danish registries.

\section{MATERIALS AND METHODS Case ascertainment}

We identified ALS cases via an extended Danish version of the International Classification of Diseases and Related Health Problems, Eighth Revision (ICD-8) codes from 1977 to 1994 and International Classification of Diseases and Related Health Problems, Tenth Revision (ICD-10) codes from 1994 to 2013 acquired from patient records included in the Danish National Patient Registry. ${ }^{21} 22$ Patients with a primary discharge diagnosis of 'amyotrophic lateral sclerosis' (ICD-8 code 348.0) or 'motor neuron disease' (ICD-10 code G12.2) were designated as ALS cases. In prior work, we found this case ascertainment to have high concordance with medical record review (93\%). ${ }^{23}$ The date of the first recorded ALS diagnosis was defined as the 'index date'. For each case, records for 100 birth year-matched and sex-matched controls alive at the time of the index date were randomly selected using the Danish Central Person Registry, ${ }^{24}$ which keeps track of vital and emigration status, and assigned the same index date. To exclude potential prevalent cases, we limited our analysis to subjects with a first recorded diagnosis on 1 January 1982 or later, 5 years after the initiation of the Danish National Patient Registry in 1977..$^{21}$

\section{Exposure assessment}

Unique Central Person numbers, assigned to all residents in Denmark since 1968, allowed for the linkage of demographic and diagnosis data to employment history data from the Danish Pension Fund. ${ }^{25}$ Employment records from the Danish Pension Fund are based on eight-digit employer tax ID numbers and five-digit industry codes derived from an extended version of International Standard Industrial Classification codes by Statistics Denmark. ${ }^{25}$ Companies in Denmark are classified into main branches based on the company's primary activities by Statistics Denmark and are categorised into 579 different entities. ${ }^{25}$ Membership of the Pension Fund is compulsory for all employees working at least 9 hours per week, and records are kept even if a person has emigrated or died. To diminish potential exposure misclassification due to work held prior to the start of the Danish Pension Fund in $1964,{ }^{26}$ we excluded subjects who were older than 25 years of age in 1964 (born before 1939), which leaves 1639 cases under study. ${ }^{24}$

Cumulative occupational $\mathrm{Pb}$ exposure was estimated using a JEM constructed by the Nordic Occupational Cancer Study for Denmark. ${ }^{27}$ Development of Nordic, and specifically Danish JEMs, have been previously described. ${ }^{27} 28$ In summary, a team of exposure experts from the five Nordic countries (Finland, Norway, Sweden, Denmark and Iceland) used the template of previously developed Finnish JEMs with information on exposure, occupations and exposure periods covering over 300 occupation categories. ${ }^{27}$ Annual mean levels of exposure for the original Finnish JEMs are based on biomonitoring data and environmental measurements to assess chemical exposures. ${ }^{28}$ Annual mean levels of exposure for the original JEMs are based on biomonitoring data and environmental measurements to assess chemical exposures. For $\mathrm{Pb}, 61023$ blood $\mathrm{Pb}$ levels and area (eg, air and dust) measurements were collected in different occupational categories. ${ }^{28}$ These measurements were used to create an estimated blood concentration $(\mu \mathrm{mol} / \mathrm{L})$ in the different occupations. This Danish JEM was modified from the Finnish JEM for relevance to Danish occupations based on industrial measurements of $\mathrm{Pb}$ and probability of exposure for each job in Denmark, with a priori time-specific measurement periods of 1945-1959, 1960-1974, 1975-1984 and after 1984. Probability of exposure was based on the Work Environment and Health in Denmark Survey, with the highest probability of $\mathrm{Pb}$ exposure belonging to those working as electronics and telecommunications workmen, telephone installation crew, linemen and cable jointers, electrical and electronic equipment assemblers, typographers and plumbers. Other exposed occupations in this JEM included machine and engine mechanics, sheet metal workers, welders, construction workers, glass and ceramic decorators and policemen.

We calculated individual exposure by multiplying the concentration and probability of exposure for each job, ${ }^{27}$ then multiplying this by the duration of employment determined by employment history acquired from the Pension Fund data. We refer to this metric as 'cumulative estimated exposure,' which was calculated as the sum of each job exposure for each participant, including matched controls, up to the index date. In our secondary analysis, we limited exposure calculations to occupations with $50 \%$ probability of exposure or more and those jobs with $<50 \%$ probability of exposure were considered unexposed. For this metric, we then calculated exposure by multiplying the expected exposure by duration of employment in each occupation and did not consider the specific probability of exposure above the 50\% threshold. We also explored 5-year and 10-year exposure lag periods before the index date (ie, excluding exposures that occurred within those time periods) to omit exposures that could have occurred during any time of undiagnosed ALS, examine possible variations in associations due to timing and mitigate potential healthy worker bias.

\section{Statistical analysis}

ALS cases and controls were classified as ever or never exposed to $\mathrm{Pb}$. Using conditional logistic regression, we obtained ORs and 95\% CIs. Cumulative estimated exposure or level was categorised with cut-points at the 30th and 60th percentiles to have three categories representing low, medium and high exposures with no exposure as the reference. Cut-points were based on the distributions among exposed controls for the 10-year lagged exposures and kept the same for the different lagged analyses for comparability. We included these categories as the primary predictive variable in our conditional logistic regression models. In multivariable analysis, we adjusted for residential location and socioeconomic status (SES) categories at the index date. SES was based on five ordered categories determined from tax-recorded occupation title as follows: (1) academics and corporate managers, (2) people with high-salary positions, (3) low-salary positions, (4) skilled workers and (5) unskilled workers. For subjects who were married at the time of the index date, SES was based on the highest SES of the participant or spouse. We removed participants with less than 5 years of total work experience from the analysis in order to avoid healthy worker hire bias. Tests for trend were based on logistic regression analysis with $\mathrm{Pb}$ measures in continuous format and scaled per $100 \mu \mathrm{mol} / \mathrm{L}$. Because employment status and expected job tasks vary greatly between men and women in this population, all analyses were stratified a prior by sex and conducted using SAS V.9.4. ${ }^{29}$ This secondary data analysis was exempt from full review by the Harvard T.H. Chan School of Public Health Institutional Review Board. 
Table 1 Demographic characteristics at the index date by lead exposure

\begin{tabular}{|c|c|c|c|c|c|c|}
\hline \multirow[b]{2}{*}{ Characteristic } & \multicolumn{2}{|c|}{ Lead unexposed $(n=93773)$} & \multicolumn{2}{|c|}{ Lead exposed $<50 \%$ probability $(\mathrm{n}=39877)$} & \multicolumn{2}{|c|}{ Lead exposed $\geq 50 \%$ probability $(n=20203)$} \\
\hline & $\mathrm{n}$ & $\%$ & $\mathrm{n}$ & $\%$ & $\mathrm{n}$ & $\%$ \\
\hline \multicolumn{7}{|l|}{ Sex } \\
\hline Male & 48304 & 51.57 & 31498 & 79.16 & 13706 & 68.00 \\
\hline Female & 45362 & 48.43 & 8292 & 20.84 & 6451 & 32.00 \\
\hline \multicolumn{7}{|l|}{ Age (years) } \\
\hline$<45$ & 11337 & 12.10 & 4862 & 12.22 & 2240 & 11.11 \\
\hline $45-54$ & 23686 & 25.29 & 10506 & 26.40 & 5224 & 25.92 \\
\hline $55-64$ & 37838 & 40.40 & 16416 & 41.26 & 8524 & 42.29 \\
\hline $65-74$ & 20805 & 22.21 & 8006 & 20.12 & 4169 & 20.68 \\
\hline \multicolumn{7}{|l|}{ Socioeconomic status* } \\
\hline Academics and managers & 12894 & 13.77 & 3003 & 7.55 & 1616 & 8.02 \\
\hline High-salary positions & 15296 & 16.33 & 4664 & 11.721 & 2653 & 13.16 \\
\hline Low-salary positions & 17761 & 18.96 & 6441 & 16.19 & 3437 & 17.05 \\
\hline Skilled workers & 25454 & 27.18 & 14979 & 37.65 & 7484 & 37.13 \\
\hline Unskilled workers & 13575 & 14.49 & 7070 & 17.77 & 3383 & 16.78 \\
\hline Unknown & 8686 & 9.27 & 3633 & 9.13 & 1584 & 7.86 \\
\hline \multicolumn{7}{|c|}{ Residence at diagnosis/index date } \\
\hline Copenhagen & 9606 & 10.26 & 3328 & 8.36 & 2337 & 11.59 \\
\hline Copenhagen suburbs & 22226 & 23.73 & 88581 & 22.26 & 6003 & 29.78 \\
\hline Aarhus/Odense & 9166 & 9.79 & 3939 & 9.90 & 1965 & 9.75 \\
\hline Provincial towns & 38703 & 41.32 & 17001 & 42.73 & 6913 & 34.30 \\
\hline Rural areas & 13664 & 14.59 & 6553 & 16.42 & 2840 & 14.09 \\
\hline Greenland & 81 & 0.09 & 31 & 0.08 & 26 & 0.13 \\
\hline Unknown & 220 & 0.23 & 100 & 0.25 & 73 & 0.36 \\
\hline \multicolumn{7}{|l|}{ Marital status } \\
\hline Married & 64619 & 68.99 & 26123 & 65.65 & 12961 & 64.30 \\
\hline Unmarried & 11755 & 12.55 & 5805 & 14.59 & 2565 & 12.73 \\
\hline Divorced & 12193 & 13.02 & 6281 & 15.79 & 3703 & 18.37 \\
\hline Widowed & 4918 & 5.25 & 1539 & 3.87 & 897 & 4.45 \\
\hline Unknown & 181 & 0.19 & 42 & 0.11 & 31 & 0.15 \\
\hline
\end{tabular}

*SES for married subjects was based on the highest SES of the participant or spouse.

\section{RESULTS}

A total of 1639 ALS cases and 151974 controls met our inclusion criteria (see online supplementary figure). As shown in table 1 , although only $52 \%$ of those never occupationally exposed to $\mathrm{Pb}$ were men, a notable $75 \%$ of those ever $\mathrm{Pb}$-exposed were men (not displayed). When demographic factors for exposed subjects were stratified by those ever working in industries with $\geq 50 \%$ probability of exposure, the proportion of men with a higher probability of exposure was slightly lower at $68 \%$. Most subjects $(>64 \%)$ were married at the time of the index date. Additionally, a greater portion of subjects who were $\mathrm{Pb}$ exposed were categorised as 'skilled workers' (37\%) compared with those who were not $\mathrm{Pb}$ exposed (27\%).

Results of our analysis of cumulative estimated exposure among men are shown in table 2. Although odds of ALS in men were consistently slightly higher for cumulative estimated exposures greater than the 60th percentile in all lag periods, none of these results were statistically significant. However, when examining expected exposure measures jobs with $\geq 50 \%$ probability of $\mathrm{Pb}$ exposure among men, exposures greater than the 60th percentile resulted in significantly higher adjusted ORs (aORs) (table 3 ) for extended lag periods of 5 years prior (aOR: $1.35 ; 95 \%$ CI 1.04 to 1.76 ) and 10 years prior to the index date (aOR: 1.33 ; 95\% CI 1.03 to 1.72 ). There was not a consistent pattern in lower exposure categories and the overall trend was not significant for any of these analyses.
Among women, the aORs were slightly elevated in the highest exposure categories, but these were not statistically significant (table 4), and there was no consistent pattern in lower cumulative estimated exposure categories. Analyses of $\mathrm{Pb}$ expected exposure among women showed no consistent pattern (table 5). Although the aOR for ALS was higher for measures greater than the 60th percentile for analyses with no lag (aOR: 1.04; 95\% CI 0.73 to 1.48 ), this was not significant (table 5).

\section{DISCUSSION}

In our nested, matched nationwide case-control study of ALS in Denmark from 1982 to 2013, we found an association between expected occupational $\mathrm{Pb}$ exposure and odds of ALS among men holding jobs with a high $(\geq 50 \%)$ probability of $\mathrm{Pb}$ exposure. It is important to note that when exposure was limited to occupations with at least $50 \%$ probability of exposure, only approximately $15 \%$ of study subjects were $\mathrm{Pb}$ exposed. The increased odds were limited to those exposed at the highest level, and results were slightly stronger when occupational exposures were limited to jobs held 5 and 10 years prior to the ALS index date. Although one study previously suggested an association between cumulative estimated exposure among women, ${ }^{5}$ we did not see any significant associations among women, which could potentially be explained by sex differences in job tasks, and thereby exposure within the same job, which is not taken 
Table 2 Analyses of cumulative estimated exposure to lead and ALS case status in men

\begin{tabular}{|c|c|c|c|c|}
\hline & Controls N (\%) & Cases N (\%) & OR $(95 \% \mathrm{CI})^{*}$ & aOR $(95 \% \mathrm{Cl}) \dagger$ \\
\hline \multicolumn{5}{|l|}{ No lag $(n=93508)$} \\
\hline No exposure & $48802(51.67)$ & $502(50.91)$ & 1.00 (Ref) & 1.00 (Ref) \\
\hline Ever exposure $(\mu \mathrm{mol} / \mathrm{L}) \ddagger$ & $44720(48.33)$ & $484(49.09)$ & $1.03(0.91$ to 1.17$)$ & 1.07 (0.93 to 1.22$)$ \\
\hline$<23.87$ & $9030(10.73)$ & $119(12.07)$ & 1.20 (0.97 to 1.48$)$ & $1.20(0.97$ to 1.49$)$ \\
\hline 23.87-102.90 & $10044(10.86)$ & $111(11.26)$ & $1.02(0.82$ to 1.28$)$ & $1.04(0.83$ to 1.20$)$ \\
\hline$>102.90$ & 24746() & $254(25.76)$ & $0.98(0.84$ to 1.15$)$ & $1.02(0.87$ to 1.20$)$ \\
\hline Test for trend & & & $1.00(0.98$ to 1.01$)$ & 1.00 (0.99 to 1.02$)$ \\
\hline \multicolumn{5}{|l|}{ 5-year lag } \\
\hline No exposure & $53250(57.55)$ & $558(56.59)$ & 1.00 (Ref) & 1.00 (Ref) \\
\hline Ever exposure $(\mu \mathrm{mol} / \mathrm{L}) \ddagger$ & $39272(42.45)$ & $428(43.41)$ & 1.05 (0.92 to 1.19$)$ & $1.08(0.94$ to 1.24$)$ \\
\hline$<23.87$ & $11337(12.25)$ & $128(12.98)$ & $1.08(0.89$ to 1.32$)$ & $1.14(0.93$ to 1.39$)$ \\
\hline 23.87-102.90 & $11365(12.28)$ & $119(12.07)$ & $1.01(0.82$ to 1.23$)$ & 1.05 (0.85 to 1.29$)$ \\
\hline$>102.90$ & $16570(17.91)$ & $181(18.36)$ & 1.05 (0.89 to 1.24$)$ & $1.06(0.89$ to 1.27$)$ \\
\hline Test for trend & & & $1.00(0.99$ to 1.01$)$ & 1.01 (0.98 to 1.04) \\
\hline \multicolumn{5}{|l|}{ 10-year lag } \\
\hline No exposure & $55274(59.74)$ & $575(58.32)$ & 1.00 (Ref) & 1.00 (Ref) \\
\hline Ever exposure $(\mu \mathrm{mol} / \mathrm{l}) \ddagger$ & $37248(40.26)$ & $411(41.68)$ & 1.07 (0.94 to 1.22$)$ & 1.10 (0.96 to 1.26$)$ \\
\hline$<23.87$ & $11186(12.09)$ & $127(12.88)$ & $1.10(0.91$ to 1.34$)$ & $1.14(0.93$ to 1.40$)$ \\
\hline 23.87-102.90 & $11161(12.06)$ & $120(12.17)$ & 1.04 (0.86 to 1.27$)$ & 1.09 (0.88 to 1.34$)$ \\
\hline$>102.90$ & $14901(16.11)$ & 164 (16.63) & 1.07 (0.90 to 1.27$)$ & $1.08(0.90$ to 1.30$)$ \\
\hline Test for trend & & & 1.01 (0.97 to 1.04$)$ & 1.01 (0.97 to 1.05$)$ \\
\hline
\end{tabular}

* Controls were individually matched to cases on age and sex.

tModels adjusted for SES and residential location.

$\ddagger$ Cumulative estimated exposure $=\left[(\text { level of exposure })^{\star} \text { (probability of exposure) } / 100\right]^{\star}$ (days employed).

ALS, amyotrophic lateral sclerosis; aOR, adjusted OR; SES, socioeconomic status.

\begin{tabular}{|c|c|c|c|c|}
\hline & Controls N (\%) & Cases N (\%) & OR $(95 \% \mathrm{Cl})^{*}$ & aOR $(95 \% \mathrm{Cl}) \dagger$ \\
\hline \multicolumn{5}{|l|}{ No lag $(n=93508)$} \\
\hline No exposure & 78975 (85.36) & 827 (83.87) & 1.00 (Ref) & 1.00 (Ref) \\
\hline Ever exposure ( $\mu \mathrm{mol} / \mathrm{L}) \ddagger$ & 13547 (14.64) & 159 (16.13) & $1.13(0.95$ to 1.33$)$ & 1.15 (0.96 to 1.38$)$ \\
\hline$<50.00$ & $3172(3.43)$ & $37(3.75)$ & 1.19 (0.85 to 1.68$)$ & 1.20 (0.85 to 1.69$)$ \\
\hline $50.00-222.00$ & $3269(3.53)$ & $33(3.35)$ & 0.92 (0.63 to 1.34$)$ & 0.93 (0.63 to 1.35$)$ \\
\hline$>222.00$ & $7106(7.68)$ & $89(9.30)$ & 1.22 (0.97 to 1.53$)$ & 1.23 (0.99 to 1.55$)$ \\
\hline Test for trend & & & 1.01 (0.99 to 1.02$)$ & 1.00 (0.99 to 1.02$)$ \\
\hline \multicolumn{5}{|l|}{ 5-year lag } \\
\hline No exposure & 81107 (87.66) & $848(86.00)$ & 1.00 (Ref) & 1.00 (Ref) \\
\hline Ever exposure ( $\mu \mathrm{mol} / \mathrm{L}) \ddagger$ & 11415 (12.34) & $138(14.00)$ & $1.16(0.97$ to 1.39$)$ & 1.19 (0.98 to 1.44$)$ \\
\hline$<50.00$ & 3276 (3.54) & 39 (3.96) & 1.14 (0.83 to 1.58$)$ & 1.22 (0.87 to 1.70$)$ \\
\hline $50.00-222.00$ & $3348(3.62)$ & $32(3.25)$ & 0.92 (0.65 to 1.31$)$ & 0.93 (0.64 to 1.35$)$ \\
\hline$>222.0$ & $4791(5.18)$ & $67(6.80)$ & $1.35(1.05$ to 1.73$)$ & 1.35 (1.04 to 1.76$)$ \\
\hline Test for trend & & & 1.02 (0.99 to 1.04$)$ & $1.01(0.99$ to 1.04$)$ \\
\hline \multicolumn{5}{|l|}{ 10-year lag } \\
\hline No exposure & 81802 (88.41) & $858(87.02)$ & 1.00 (Ref) & 1.00 (Ref) \\
\hline Ever exposure ( $\mu \mathrm{mol} / \mathrm{L}) \ddagger$ & $10720(11.59)$ & $128(12.98)$ & 1.15 (0.95 to 1.38$)$ & 1.16 (0.95 to 1.41$)$ \\
\hline$<50.00$ & $3208(3.47)$ & $37(3.75)$ & 1.11 (0.80 to 1.54$)$ & 1.16 (0.83 to 1.64$)$ \\
\hline $50.00-222.00$ & $3223(3.48)$ & $32(3.25)$ & 0.95 (0.67 to 1.36$)$ & 0.95 (0.65 to 1.38$)$ \\
\hline$>222.00$ & $4289(4.64)$ & $59(5.98)$ & $1.32(1.01$ to 1.73$)$ & 1.33 (1.03 to 1.72$)$ \\
\hline Test for trend & & & 1.01 (0.99 to 1.05$)$ & 1.01 (0.98 to 1.04$)$ \\
\hline \multicolumn{5}{|c|}{$\begin{array}{l}\text { Bold values are statistically significant }(p<0.05) \\
\text { *Controls were individually matched to cases on age and sex. } \\
\text { †Models adjusted for SES and residential location. } \\
\text { †Cumulative expected exposure=level of exposure*days employed for jobs with }>50 \% \text { probability of exposure. } \\
\text { ALS, amyotrophic lateral sclerosis; aOR, adjusted OR; SES, socioeconomic status. }\end{array}$} \\
\hline
\end{tabular}


Table 4 Analyses of cumulative estimated exposure to lead and ALS case status in women

\begin{tabular}{|c|c|c|c|c|}
\hline & Controls N (\%) & Cases N (\%) & OR $(95 \% \mathrm{Cl})^{*}$ & aOR $(95 \% \mathrm{Cl}) \dagger$ \\
\hline \multicolumn{5}{|l|}{ No lag $(n=60105)$} \\
\hline No exposure & 44867 (75.47) & $495(75.80)$ & 1.00 (Ref) & 1.00 (Ref) \\
\hline Ever exposure ( $\mu \mathrm{mol} / \mathrm{L}) \neq$ & $14585(24.53)$ & $158(24.20)$ & 0.99 (0.82 to 1.18$)$ & 1.01 (0.83 to 1.21$)$ \\
\hline$<17.40$ & $3566(6.00)$ & $37(5.67)$ & 0.95 (0.68 to 1.33 ) & 0.94 (0.66 to 1.34 ) \\
\hline $17.40-72.89$ & $3663(6.16)$ & $39(5.97)$ & 0.97 (0.70 to 1.34 ) & 1.03 (0.74 to 1.31$)$ \\
\hline$>72.89$ & $7356(12.37)$ & $82(12.56)$ & 1.01 (0.80 to 1.28$)$ & $1.03(0.80$ to 1.31$)$ \\
\hline Test for trend & & & 1.00 (0.97 to 1.04$)$ & 1.00 (0.97 to 1.04$)$ \\
\hline \multicolumn{5}{|l|}{ 5-year lag } \\
\hline No exposure & $46938(78.95)$ & $514(78.71)$ & 1.00 (Ref) & 1.00 (Ref) \\
\hline Ever exposure ( $\mu \mathrm{mol} / \mathrm{L}) \ddagger$ & $12514(21.05)$ & $139(21.29)$ & 1.00 (0.84 to 1.20$)$ & 1.02 (0.85 to 1.24$)$ \\
\hline$<17.40$ & $3675(6.18)$ & $40(6.13)$ & 1.00 (0.73 to 1.39$)$ & 0.99 (0.70 to 1.39$)$ \\
\hline $17.40-72.89$ & $3678(6.19)$ & $44(6.74)$ & 1.10 (0.81 to 1.50$)$ & 1.14 (0.83 to 1.56$)$ \\
\hline$>72.89$ & $5161(8.68)$ & $55(8.42)$ & 0.98 (0.74 to 1.30$)$ & 1.00 (0.75 to 1.34$)$ \\
\hline Test for trend & & & 1.01 (0.95 to 1.07$)$ & 1.02 (0.95 to 1.08$)$ \\
\hline \multicolumn{5}{|l|}{ 10-year lag } \\
\hline No exposure & $47637(80.13)$ & $520(79.63)$ & 1.00 (Ref) & 1.00 (Ref) \\
\hline Ever exposure ( $\mu \mathrm{mol} / \mathrm{L}) \ddagger$ & 11815 (19.87) & $133(20.37)$ & 1.04 (0.86 to 1.26$)$ & 1.04 (0.85 to 1.27$)$ \\
\hline$<17.40$ & $3544(5.96)$ & $39(6.73)$ & 1.02 (0.74 to 1.36$)$ & 1.00 (0.71 to 1.41$)$ \\
\hline $17.40-72.89$ & 3545 (5.96) & $44(6.74)$ & 1.15 (0.84 to 1.56$)$ & 1.17 (0.85 to 1.61$)$ \\
\hline$>72.89$ & $4726(7.95)$ & $50(7.66)$ & 0.98 (0.73 to 1.31$)$ & 0.98 (0.72 to 1.32$)$ \\
\hline Test for trend & & & 1.00 (0.93 to 1.07$)$ & 1.01 (0.94 to 1.08$)$ \\
\hline
\end{tabular}

${ }^{*}$ Controls were individually matched to cases on age and sex.

tModels adjusted for SES and residential location.

$\ddagger$ Cumulative estimated exposure $=\left[\left(\right.\right.$ level of exposure ${ }^{*}$ (probability of exposure)/100] ${ }^{*}$ (days employed).

ALS, amyotrophic lateral sclerosis; aOR, adjusted OR; SES, socioeconomic status.

into account by our JEM. We examined potential associations in women using cut-points based on levels estimated in men and still saw no statistically significant results, suggesting that associations seen in men are not strictly due to industry exposure levels but may be due to job differences, although differences in underlying biological responses to $\mathrm{Pb}$ exposure cannot

\begin{tabular}{|c|c|c|c|c|}
\hline$n=60105$ & Controls N (\%) & Cases N (\%) & OR $(95 \% \mathrm{Cl})^{*}$ & aOR $(95 \% \mathrm{Cl}) \dagger$ \\
\hline \multicolumn{5}{|l|}{ No lag } \\
\hline No exposure & $53073(89.27)$ & $581(88.97)$ & 1.00 (Ref) & 1.00 (Ref) \\
\hline Ever exposure $(\mu \mathrm{mol} / \mathrm{L}) \ddagger$ & $6379(10.73)$ & $72(11.03)$ & 1.04 (0.81 to 1.33$)$ & 1.07 (0.83 to 1.38$)$ \\
\hline$<46.00$ & $1560(2.62)$ & $20(3.06)$ & 1.18 (0.75 to 1.84$)$ & 1.17 (0.73 to 1.88$)$ \\
\hline $46.00-178.50$ & $1638(2.76)$ & $17(2.60)$ & 0.95 (0.59 to 1.54$)$ & 1.07 (0.66 to 1.73 ) \\
\hline$>178.50$ & 3181 (5.35) & $35(5.36)$ & $1.01(0.72$ to 1.43$)$ & 1.04 (0.73 to 1.48 ) \\
\hline Test for trend & & & $1.00(0.99$ to 1.03$)$ & 1.01 (0.98 to 1.03 ) \\
\hline \multicolumn{5}{|l|}{ 5-year lag } \\
\hline No exposure & 53952 (90.75) & $590(90.35)$ & 1.00 (Ref) & 1.00 (Ref) \\
\hline Ever exposure $(\mu \mathrm{mol} / \mathrm{L}) \ddagger$ & $5500(9.25)$ & $63(9.65)$ & 1.05 (0.81 to 1.37$)$ & 1.08 (0.82 to 1.42$)$ \\
\hline$<46.00$ & $1590(2.67)$ & $21(3.22)$ & 1.21 (0.78 to 1.88$)$ & 1.20 (0.76 to 1.91$)$ \\
\hline $46.00-178.50$ & $1620(2.72)$ & $18(2.76)$ & 1.02 (0.64 to 1.46$)$ & 1.06 (0.65 to 1.73$)$ \\
\hline$>178.20$ & $2290(3.85)$ & $24(3.68)$ & 0.97 (0.64 to 1.46$)$ & 1.00 (0.66 to 1.53 ) \\
\hline Test for trend & & & $1.00(0.96$ to 1.05$)$ & 1.00 (0.96 to 1.05$)$ \\
\hline \multicolumn{5}{|l|}{ 10-year lag } \\
\hline No exposure & $54274(91.29)$ & $595(91.12)$ & 1.00 (Ref) & 1.00 (Ref) \\
\hline Ever exposure $(\mu \mathrm{mol} / \mathrm{L}) \ddagger$ & $5178(8.71)$ & $58(8.88)$ & 1.03 (0.79 to 1.35$)$ & 1.04 (0.78 to 1.37 ) \\
\hline$<46.00$ & $1549(2.61)$ & $19(2.91)$ & $1.13(0.71$ to 1.79$)$ & 1.09 (0.67 to 1.78$)$ \\
\hline $46.00-178.50$ & $1555(2.61)$ & $18(2.76)$ & $1.06(0.66$ to 1.71$)$ & 1.09 (0.67 to 1.78$)$ \\
\hline$>178.50$ & $2074(3.49)$ & $21(3.22)$ & 0.93 (0.60 to 1.44$)$ & 0.95 (0.60 to 1.49$)$ \\
\hline Test for trend & & & 0.98 (0.93 to 1.04$)$ & 1.00 (0.93 to 1.05$)$ \\
\hline
\end{tabular}

${ }^{*}$ Controls were individually matched to cases on age and sex.

tModels adjusted for SES and residential location.

$\ddagger$ Cumulative expected exposure=level of exposure* days employed for jobs with $>50 \%$ probability of exposure.

ALS, amyotrophic lateral sclerosis; aOR, adjusted OR; SES, socioeconomic status. 
be ruled out. Notably, we had fewer exposed female cases than male cases, as well as fewer women with at least 5 years of work experience, which could also have contributed to the observed differences in associations.

$\mathrm{Pb}$ is known to have adverse neurodegenerative effects. ${ }^{30}$ Additionally, as $\mathrm{Pb}$ can accumulate over years and be stored in bone, it can later be metabolised and mobilise to other tissues, including the brain, where it can easily cross the blood-brain barrier into neural tissues. ${ }^{31}$ Therefore, several studies have investigated associations between ALS and $\mathrm{Pb}$ exposure using various biomarkers, including cerebrospinal fluid, ${ }^{32}$ blood ${ }^{33} 34$ and bone. ${ }^{34}$ Although some $\mathrm{Pb}$ biomarker studies have indicated significantly elevated associations with risk of ALS, ${ }^{33}$ other studies reported elevated, but not significant, associations. ${ }^{32}$ However, with the exception of bone $\mathrm{Pb}$, a major problem in using biomarkers as a measure for $\mathrm{Pb}$ exposure is that they may not capture historical exposures and thus would not serve as a relevant indicator of neurotoxicity experienced for several years prior to ALS diagnosis. Considering studies showing increased risk of ALS in people working certain occupations with consistent $\mathrm{Pb}$ exposure, estimates of $\mathrm{Pb}$ exposure via occupation history is potentially a better exposure measurement than biomarkers with short half-lives for $\mathrm{Pb}$. It is important to note that earlier studies of occupation exposures were based on retrospectively collected occupation data in small samples. ${ }^{19} 35$ Importantly, however, these studies examined specific jobs individually, each of which may have involved many exposures. Our study is the first to estimate $\mathrm{Pb}$ exposure across all jobs by using an objective JEM with prospectively and objectively collected population-based employment history. The use of a JEM to estimate participants' cumulative exposures to $\mathrm{Pb}$ allows for better estimations of total exposure specifically to $\mathrm{Pb}$ across all jobs held and consideration of aspects of timing of exposures relative to disease onset.

Despite the unparalleled data source used for this study, we acknowledge that there are some limitations. As we did not have information on smoking status of subjects, which has been suggested as a potential risk factor for ALS, ${ }^{36}{ }^{37}$ we could not adjust for smoking as a potential confounder in our multivariable analyses. However, by adjusting for SES in our analyses, which has been correlated with smoking habits in Denmark, ${ }^{38}$ we likely indirectly adjusted for smoking status. Additionally, there is evidence that positive associations of ALS and smoking seen in other studies may be more prominent among women than in men. ${ }^{39}{ }^{40}$ Thus, the positive results seen only in men in our study may not be fully consistent with smoking as a residual confounder.

There is unavoidable measurement error relative to actual personal exposures with use of a JEM to estimate $\mathrm{Pb}$ exposures. Using the product of probability and level of exposure to calculate cumulative exposure indices may introduce exposure misclassification, particularly in occupations with low probability of exposure. ${ }^{41}$ Therefore, attenuation bias would likely be observed for the results of associations between $\mathrm{Pb}$ exposure and ALS. ${ }^{42}$ However, in the process of modifying the Finnish JEM to construct the Danish JEM, priority for classification was given to occupations with high exposures, ${ }^{28}$ which potentially reduces this bias. Additionally, it has been suggested that focusing analyses on occupations with a greater probability of exposure should reduce the risk of misclassification, ${ }^{41}$ and this is what we have done in reporting exposures based on occupations with $>50 \%$ probability in tables 3 and 5 . Although exposure estimates from 1945 to 1959 were meagre due to lack of available data, ${ }^{27}$ measurement data were available after this point, and only occupations held after 1964, the year the Danish Pension
Fund was established, were included in our analysis. Due to the employment history registry beginning on 1 April 1964, some exposure misclassification may have been introduced for subjects employed prior to that date, as we were unable to determine exposures for any jobs held before that time point. However, we attempted to minimise this misclassification by restricting the analysis to those who were 25 years or younger at the start of the Pension Fund. Finally, the validation of the specific JEM used for this study is limited and indirect, although its construction was based on biosample testing of $\mathrm{Pb}$ levels among thousands of workers in difference occupations. Some evidence of the validity is provided by studies with the original Finnish JEM, as well as those similarly adapted for Norway and Sweden that replicated established associations (or lack of) with cancer risk. ${ }^{43} 44$ Additionally, all JEMs for the Nordic Occupational Cancer Study are edited as necessary if new information becomes available to improve on estimates and are re-evaluated by numerous experts on a consistent basis. ${ }^{28}$ However, we also acknowledge that the priority given to high-exposure occupations ${ }^{28}$ and subsequent omission of occupations with lower exposures (<5\% probability), could reduce the sensitivity of this JEM.

This was, to our knowledge, the first study to estimate cumulative occupational $\mathrm{Pb}$ exposure in relation to ALS. Our results suggest that, at least for men, those exposed at the highest levels are at higher risk of ALS for those with a greater probability of exposure. Although $\mathrm{Pb}$ exposures in the general population have been significantly mitigated over the past few decades, there are populations that still experience high $\mathrm{Pb}$ exposures, in particular certain occupations such as construction work. Additionally, as some population exposures to $\mathrm{Pb}$ through residential proximity to industrial facilities, hobbies such as hunting and fishing, home renovation activities and smoking are still prevalent, further action may need to be taken to expand on mechanisms for reducing $\mathrm{Pb}$ exposure from other sources. Lastly, understanding the biological mechanisms by which $\mathrm{Pb}$ may increase risk of ALS could help further understand ALS pathophysiology.

Contributors MGW and JH designed the study and directed its implementation. JH and OG gathered data. ASD performed data analysis and drafted the article. MGW, $\mathrm{JH}$ and AJS revised the manuscript.

Funding This work was supported by the National Institute of Environmental Health Sciences (grants R01 ES019188 and P30 ES000002 to MGW). ASD was supported in part by a National Institutes of Health training grant (grant T32 ES007069).

\section{Competing interests None declared.}

\section{Patient consent for publication Not required.}

Ethics approval This study was approved by the Danish Data Protection Agency. Because this study was a secondary analysis, it was determined to be exempt from full review by the Harvard T.H. Chan School of Public Health Institutional Review Board.

Provenance and peer review Not commissioned; externally peer reviewed.

\section{REFERENCES}

1 Brown RH, Al-Chalabi A. Amyotrophic Lateral Sclerosis. N Engl J Med 2017;377:162-72.

2 Seals RM, Hansen J, Gredal 0, et al. Age-period-cohort analysis of trends in amyotrophic lateral sclerosis in Denmark,1970-2009. Am J Epidemiol 2013:178:1265-71.

3 Hardiman 0, Al-Chalabi A, Chio A, et al. Amyotrophic lateral sclerosis. Nat Rev Dis Primers 2017;3:17071.

4 Al-Chalabi A, Hardiman 0. The epidemiology of ALS: a conspiracy of genes, environment and time. Nat Rev Neurol 2013;9:617-28.

5 Weuve J, Korrick SA, Weisskopf MG, et al. Cumulative exposure to lead in relation to cognitive function in older women. Environ Health Perspect 2009;117:574-80.

6 Sanders T, Liu Y, Buchner V, et al. Neurotoxic effects and biomarkers of lead exposure: a review. Rev Environ Health 2009;24:15-45. 
7 Kerper LE, Hinkle PM. Lead uptake in brain capillary endothelial cells: activation by calcium store depletion. Toxicol App/ Pharmacol 1997;146:127-33.

8 Bressler JP, Goldstein GW. Mechanisms of lead neurotoxicity. Biochem Pharmacol 1991:41:479-84.

9 Qian Y, Zheng Y, Ramos KS, et al. The involvement of copper transporter in leadinduced oxidative stress in astroglia. Neurochem Res 2005;30:429-38.

10 Weisskopf MG, Proctor SP, Wright RO, et al. Cumulative lead exposure and cognitive performance among elderly men. Epidemiology 2007;18:59-66.

11 Weisskopf MG, Weuve J, Nie H, et al. Association of cumulative lead exposure with Parkinson's disease. Environ Health Perspect 2010;118:1609-13.

12 Wang MD, Little J, Gomes J, et al. Identification of risk factors associated with onset and progression of amyotrophic lateral sclerosis using systematic review and metaanalysis. Neurotoxicology 2017;61:101-30.

13 Fang F, Quinlan P, Ye W, et al. Workplace exposures and the risk of amyotrophic latera sclerosis. Environ Health Perspect 2009;117:1387-92.

14 Dickerson AS, Hansen J, Kioumourtzoglou MA, et al. Study of occupation and amyotrophic lateral sclerosis in a Danish cohort. Occup Environ Med 2018;75:630-8.

15 Seals RM, Kioumourtzoglou MA, Hansen J, et al. Amyotrophic lateral sclerosis and the military: A population-based study in the danish registries. Epidemiology 2016;27:188-93.

16 Peters TL, Kamel F, Lundholm C, et al. Occupational exposures and the risk of amyotrophic lateral sclerosis. Occup Environ Med 2017;74:87-92.

17 Sutedja NA, Fischer K, Veldink JH, et al. What we truly know about occupation as a risk factor for ALS: a critical and systematic review. Amyotroph Lateral Scler 2009; 10(5-6):295-301.

18 Park RM, Schulte PA, Bowman JD, et al. Potential occupational risks for neurodegenerative diseases. Am J Ind Med 2005;48:63-77.

19 McGuire V, Longstreth WT, Nelson LM, et al. Occupational exposures and amyotrophic lateral sclerosis. A population-based case-control study. Am J Epidemiol 1997; 145:1076-88.

20 Bello A, Woskie SR, Gore R, et al. Retrospective assessment of occupational exposures for the GENEVA study of als among military veterans. Ann Work Expo Health 2017:61:299-310.

21 Schmidt M, Schmidt SA, Sandegaard JL, et al. The Danish National Patient Registry: a review of content, data quality, and research potential. Clin Epidemiol 2015;7:449-90.

22 Pedersen $\mathrm{C}$, Poulsen $\mathrm{AH}$, Rod NH, et al. Occupational exposure to extremely lowfrequency magnetic fields and risk for central nervous system disease: an update of a Danish cohort study among utility workers. Int Arch Occup Environ Health 2017:90.

23 Kioumourtzoglou MA, Seals RM, Himmerslev L, et al. Comparison of diagnoses of amyotrophic lateral sclerosis by use of death certificates and hospital discharge data in the Danish population. Amyotroph Lateral Scler Frontotemporal Degener 2015;16(3-4):224-9.

24 Pedersen CB, Gøtzsche H, Møller JO, et al. The danish civil registration system. A cohort of eight million persons. Dan Med Bull 2006;53:441-9.

25 Hansen J, Lassen CF. The supplementary pension fund register. Scand J Public Health 2011;39(7 Suppl):99-102.
26 Applebaum KM, Malloy EJ, Eisen EA. Left truncation, susceptibility, and bias in occupational cohort studies. Epidemiology 2011;22:599-606.

27 Kauppinen T, Heikkilä P, Plato N, et al. Construction of job-exposure matrices for the Nordic Occupational Cancer Study (NOCCA). Acta Oncol 2009:48:791-800.

28 Kauppinen T, Uuksulainen S, Saalo A, et al. Use of the Finnish Information System on Occupational Exposure (FINJEM) in epidemiologic, surveillance, and other applications. Ann Occup Hyg 2014;58:380-96.

29 SAS Insititute Inc [computer program]. Version 9.4. Cary, NC: SAS Institute Inc, 2013.

30 Thomson RM, Parry GJ. Neuropathies associated with excessive exposure to lead. Muscle Nerve 2006:33:732-41.

31 Maret W. The Bioinorganic Chemistry of Lead in the Context of Its Toxicity. Met lons Life Sci 2017;17.

32 Vinceti M, Filippini T, Mandrioli J, et al. Lead, cadmium and mercury in cerebrospinal fluid and risk of amyotrophic lateral sclerosis: A case-control study. J Trace Elem Med Biol 2017:43:121-5.

33 Fang F, Kwee LC, Allen KD, et al. Association between blood lead and the risk of amyotrophic lateral sclerosis. Am J Epidemiol 2010;171:1126-33.

34 Kamel F, Umbach DM, Munsat TL, et al. Lead exposure and amyotrophic lateral sclerosis. Epidemiology 2002;13:311-9.

35 Kamel F, Umbach DM, Hu H, et al. Lead exposure as a risk factor for amyotrophic lateral sclerosis. Neurodegener Dis 2005;2(3-4):195-201.

36 de Jong SW, Huisman MH, Sutedja NA, et al. Smoking, alcohol consumption, and the risk of amyotrophic lateral sclerosis: a population-based study. Am J Epidemiol 2012;176:233-9.

37 Wang H, O'Reilly ÉJ, Weisskopf MG, et al. Smoking and risk of amyotrophic lateral sclerosis: a pooled analysis of 5 prospective cohorts. Arch Neurol 2011;68:207-13.

38 Osler M. Smoking habits in Denmark from 1953 to 1991: a comparative analysis of results from three nationwide health surveys among adult Danes in1953-1954,19861987 and1990-1991. Int J Epidemio/ 1992;21:862-71.

39 Weisskopf MG, McCullough ML, Calle EE, et al. Prospective study of cigarette smoking and amyotrophic lateral sclerosis. Am J Epidemiol 2004;160:26-33.

40 Alonso A, Logroscino G, Hernán MA. Smoking and the risk of amyotrophic lateral sclerosis: a systematic review and meta-analysis. J Neurol Neurosurg Psychiatry 2010;81:1249-52.

41 Burstyn I, Lavoué J, Van Tongeren M. Aggregation of exposure level and probability into a single metric in job-exposure matrices creates bias. Ann Occup Hyg 2012:56:1038-50.

42 Kim HM, Richardson D, Loomis D, et al. Bias in the estimation of exposure effects with individual- or group-based exposure assessment. J Expo Sci Environ Epidemiol 2011;21:212-21.

43 Pukkala E, Guo J, Kyyrönen P, et al. National job-exposure matrix in analyses of census-based estimates of occupational cancer risk. Scand J Work Environ Health 2005;31:97-107.

44 Togawa K, Le Cornet C, Feychting M, et al. Parental occupational exposure to heavy metals and welding fumes and risk of testicular germ cell tumors in offspring: a registry-based case-control study. Cancer Epidemiology Biomarkers \&amp; Prevention 2016 